\title{
Blood pressure response to glucose potassium insulin therapy in patients with acute stroke with mild to moderate hyperglycaemia
}

\author{
J F Scott, G M Robinson, J M French, J E O'Connell, K G M M Alberti, C S Gray
}

School of Clinical

Medical Sciences, University of

Newcastle-upon-Tyne, UK

J F Scott

J E O'Connell

K G M M Alberti

C S Gray

Department of

Statistics

J M French

City Hospitals

Sunderland NHS

Trust, Sunderland, UK

G M Robinson

J E O’Connell

Correspondence to: Professor C S Gray,

University Department of

Medicine for the Elderly, F

Floor, Sunderland Royal

Hospital, Kayll Road,

Sunderland SR4 7TP, UK

chris.gray@chs.northy.nhs.uk

Received 12 June 2000 and in revised form

6 November 2000

Accepted 10 November 2000

\begin{abstract}
Insulin is neuroprotective in animal stroke models but its effects in acute stroke in humans are unknown. The Glucose Insulin in Stroke Trial (GIST-UK) is a randomised controlled trial investigating the benefits of maintaining euglycaemia in hyperglycaemic patients with acute stroke. Data are reported from a GIST-UK substudy which sought to determine the influence of glucose potassium insulin (GKI) infusion on blood pressure in acute stroke. All adult patients admitted to hospital with acute stroke with hyperglycaemia (plasma glucose 6.1-17 mmol/1) were potentially eligible. Randomised patients received either a GKI infusion $(500 \mathrm{ml} 10 \%$ glucose, $20 \mathrm{mmol}$ potassium chloride, 16 units of insulin) or control therapy with $154 \mathrm{mmol} / 1(0.9 \%)$ saline at $100 \mathrm{ml} / \mathrm{h}$ for 24 hours. BM test strip glucose monitoring was performed 2 hourly, blood pressure monitoring 4 hourly, and plasma glucose sampling 8 hourly. Insulin concentration in the GKI infusate was altered according to test strip values to maintain test strip values between 4-7 $\mathrm{mmol} / \mathrm{l}$ in the GKI group. Neurological impairment was determined using the European stroke scale (ESS). 145 patients were studied ( 73 GKI, 72 control). Mean systolic blood pressure was significantly lower during GKI infusion between 4 hours and 24 hours except at 8 hours. Median total ESS scores improved significantly between admission and day 7 in the GKI group $(p<0.001)$ although there was no significant difference in total ESS score between groups at day 7 . The significant reduction of systolic blood pressure in acute stroke associated with GKI therapy was not associated with neurological deterioration and may have been beneficial.

(F Neurol Neurosurg Psychiatry 2001;70:401-404)
\end{abstract}

Keywords: stroke; hyperglycaemia; blood pressure

There is still no simple, safe, effective treatment for most patients with acute stroke. ${ }^{12}$ Metabolic factors that may influence outcome such as blood pressure, body temperature, and plasma glucose concentration have also been studied but few data exist on how these variables should be managed. Hyperglycaemia in acute stroke is of particular interest because it is common, strongly associated with an adverse prognosis, and is easily modified by simple intervention. ${ }^{34}$

About $75 \%$ of patients with acute stroke are hypertensive on admission to hospital. ${ }^{5} \mathrm{Al}-$ though hypertension resolves in most, around $30 \%$ of patients remain hypertensive at 1 week. ${ }^{6}$ Initial blood pressure is related to outcome in that severe hypertension and hypotension carry a relatively poor prognosis, but it is uncertain whether modulation of blood pressure to optimal levels in the acute phase alters outcome. ${ }^{7}$ The Glucose Insulin in Stroke Trial (GIST-UK) is the first ever randomised controlled trial to investigate the potential benefits of euglycaemia in hyperglycaemic patients with acute stroke. ${ }^{8}$ The trial aims to recruit 1200 patients with acute stroke from active centres in the north of England and Scotland by summer 2002. Primary end points comprise mortality from all causes at 3 months and a combined end point of death and severe disability (modified Rankin score $>3$ ). Secondary end points consist of neurological impairment (European stroke scale score) and function (Barthel index). Measurement of the blood pressure response to glucose potassium insulin (GKI) infusion in patients with acute stroke has allowed investigation of the haemodynamic effects of exogenous insulin under euglycaemic conditions.

\section{Methods}

This substudy received approval from Sunderland local research ethics committee. All patients older than 18 years admitted to Sunderland Royal Hospital with a clinical diagnosis of acute stroke (established by CT postrandomisation) within 24 hours of onset were screened to determine admission plasma glucose. Patients presenting after 24 hours or with heart failure (New York Heart Association grades 3/4), renal failure (creatinine $\geqslant 200 \mu \mathrm{mol} / 1$ or urea $\geqslant 20 \mathrm{mmol} / \mathrm{l}$ ), anaemia $(\mathrm{Hb}<9 \mathrm{~g} / \mathrm{dl})$, coma (Glasgow coma scale motor 
Baseline laboratory and demographic data in the two treatment groups

\begin{tabular}{|c|c|c|c|}
\hline & $\begin{array}{l}G K I \\
(n=73)\end{array}$ & $\begin{array}{l}\text { Control } \\
(n=72)\end{array}$ & $p$ Value \\
\hline \multicolumn{4}{|l|}{ Demographic data: } \\
\hline Sex (male/female) (n) & $36 / 37$ & & 0.56 \\
\hline Median age (y (range)) & $74(40-97)$ & $75(48-93)$ & 0.37 \\
\hline History of hypertension (n (\%)) & $27(37)$ & $29(40)$ & 0.68 \\
\hline History of ischaemic heart disease (n (\%)) & $25(34)$ & $16(22)$ & 0.19 \\
\hline History of diabetes mellitus (n (\%)) & $10(14)$ & $10(14)$ & 0.97 \\
\hline History of stroke (n (\%)) & $8(11)$ & $8(11)$ & 0.97 \\
\hline \multicolumn{4}{|l|}{ Stroke pathology: } \\
\hline Infarction (n (\%)) & $58(79)$ & $48(67)$ & \\
\hline Haemorrhage (n (\%)) & $10(14)$ & $13(18)$ & \\
\hline Haemorrhagic infarct (n (\%)) & $1(2)$ & $1(2)$ & \\
\hline Unknown (n (\%)) & $3(6)$ & $10(14)$ & 0.62 \\
\hline \multicolumn{4}{|l|}{ Clinical stoke subtype: } \\
\hline TACS $(\mathrm{n}(\%))$ & $38(52)$ & $35(48)$ & \\
\hline PACS (n (\%)) & $22(30)$ & $25(34)$ & \\
\hline LACS (n (\%)) & $13(17)$ & $7(10)$ & \\
\hline POCS (n (\%)) & $0(-)$ & $5(7)$ & 0.07 \\
\hline \multicolumn{4}{|l|}{ Clinical and laboratory measurements: } \\
\hline Median time from stroke to infusion (h (range)) & $13(3-24)$ & $11(2-24)$ & 0.49 \\
\hline Median time from admission to infusion (h (range)) & $7(1-23)$ & $6(1-22)$ & 0.64 \\
\hline Mean admission serum cortisol (nmol/1 (SD)) & $716(413)$ & $641(344)$ & 0.30 \\
\hline Mean admission plasma glucose $(\mathrm{mmol} / \mathrm{l}(\mathrm{SD}))$ & $8.8(2.3)$ & $8.6(2.1)$ & 0.38 \\
\hline Mean admission plasma sodium (mmol/1 (SD)) & $140(2.9)$ & $139(3.7)$ & 0.06 \\
\hline Mean admission plasma potassium (mmol/1 (SD)) & $3.86(0.40)$ & $3.82(0.52)$ & 0.62 \\
\hline Mean plasma potassium at $24 \mathrm{~h}(\mathrm{mmol} / \mathrm{l}(\mathrm{SD}))$ & $4.13(0.54)$ & $3.80(0.38)$ & $0.001^{\star}$ \\
\hline Mean admission plasma urea $(\mathrm{mmol} / \mathrm{l}(\mathrm{SD}))$ & $6.6(2.1)$ & $6.4(2.3)$ & 0.47 \\
\hline Mean admission plasma creatinine ( $\mu \mathrm{mol} / 1$ (SD)) & $106(25)$ & $105(25)$ & 0.62 \\
\hline
\end{tabular}

${ }^{\star} \mathrm{p}<0.05$; Mann-Whitney $U$ test.

TACS $=$ Total anterior circulation syndrome; PACS $=$ partial anterior circulation syndrome; LACS=lacunar syndrome; POCS=posterior circulation syndrome.

subscore $<4$ ), previous disabling stroke (modified Rankin score $>3$ ), dementia, isolated posterior circulation syndromes without physical disability, pure language disorders, insulin treated diabetes mellitus (type 1 or 2 ), or subarachnoid haemorrhage were excluded. All remaining patients with plasma glucose concentrations between 6.1 and $17 \mathrm{mmol} / 1$ who gave informed consent (or informed assent from the relative or care giver) were randomised. Trial treatment consisted of a com-

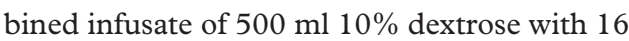
$\mathrm{U}$ human soluble insulin (Actrapid ${ }^{\circledR}$, Novo Nordisk, Denmark) and $20 \mathrm{mmol}$ potassium

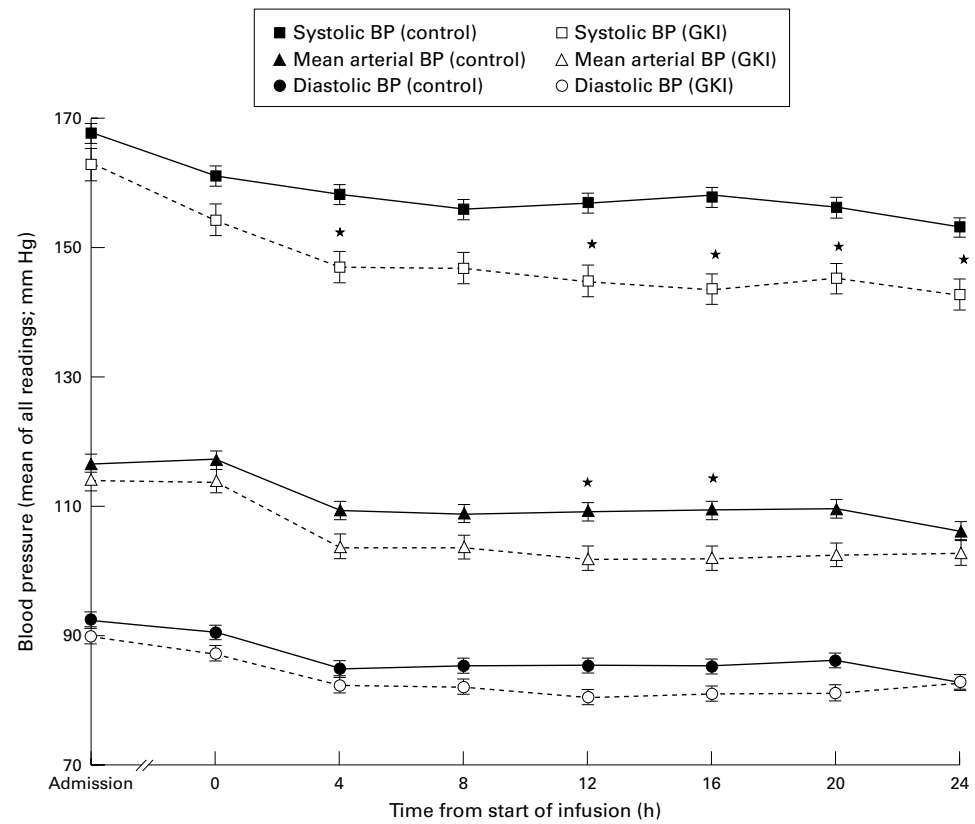

Mean of systolic, diastolic, and mean (SEM) arterial blood pressure profiles in GKI and control treated patients with acute stroke during the 24 hour trial infusion period. $p<0.05$ in mean blood pressure between groups (two tailed Student's t test). chloride (GKI); control treatment was $500 \mathrm{ml}$ $154 \mathrm{mmol} / \mathrm{l}$ saline. Treatment was administered through a peripheral vein in the nonparetic arm at a fixed rate of $100 \mathrm{ml} / \mathrm{h}$. Monitoring was identical for each infusion. Blood pressure and pulse were taken at 4 hourly intervals in the paretic arm with an electronic sphygmomanometer and plasma glucose samples were obtained at 8 hourly intervals. Monitoring with BM Glycaemie ${ }^{\circledR}$ test strips (Boehringer Mannheim, Germany) was 2 hourly, with the aim of keeping test strip values between 4 and $7 \mathrm{mmol} / 1$ in the GKI group by altering insulin concentration in the GKI accordingly. No action was taken on the test strip values in the control group unless the value rose to $>17 \mathrm{mmol} / 1$, in which case intervention with GKI was instituted. The trial infusate ran for 24 hours or until $2400 \mathrm{ml}$ was administered. Venous blood samples for electrolytes, urea, creatinine, and glucose were taken at randomisation, 24 hours, and 48 hours. All antihypertensive therapy was discontinued on admission. Clinical assessments were undertaken at randomisation, 24 hours, 48 hours, and 7 days.

\section{Results}

Over a 18 month period 631 consecutive patients with acute stroke were screened. Four hundred and eighty patients $(76 \%)$ were excluded due to admission plasma glucose $<6.1 \mathrm{mmol} / 1 \quad(\mathrm{n}=196,31 \%)$, presentation $>24$ hours $(n=167,26 \%)$, coma ( $n=64$, $10 \%)$, dementia $(\mathrm{n}=45,7 \%)$, previous disabling stroke $(n=30,5 \%)$, pure language disorders $(n=26,4 \%)$, previously diagnosed insulin treated type 1 or type 2 diabetes mellitus $(\mathrm{n}=18,3 \%)$, plasma glucose $>17 \mathrm{mmol} / \mathrm{l}$ $(n=17,3 \%)$, renal failure $(n=16,3 \%)$, posterior circulation event without peripheral motor disability $(n=13,2 \%)$, rapidly improving neurological deficit $(n=12,2 \%)$, cardiac failure $(n=7,1 \%)$, and anaemia $(n=7,1 \%)$. Of the 480 patients excluded, $138(29 \%)$ satisfied multiple exclusion criteria. Informed consent or assent was gained from 151 (98\%) of 154 eligible patients or their relatives or care givers. Seventy eight patients were randomised to GKI therapy and 73 to control treatment. Six patients were withdrawn from the study because of pneumonia $(n=1)$, subdural haematoma $(n=1)$, cerebral tumour $(n=2)$, admission glucose $>17 \mathrm{~mol} / 1 \quad(\mathrm{n}=1)$, and withdrawal of consent $(n=1)$. One hundred and forty five patients were therefore included in this analysis (table).There were no significant differences between the two groups at baseline (table). Therapy with GKI was associated with a significant reduction in mean systolic blood pressure at each 4 hourly measurement point between 4 and 24 hours $(\mathrm{p}<0.05$, two tailed Student's $t$ test) except at 8 hours $(\mathrm{p}=0.12$, figure). Mean arterial blood pressure (diastolic pressure+(systolic pressure -diastolic pressure)/3) was significantly lower in the GKI group at 12 and 16 hours. Mean diastolic blood pressure and heart rate were lower in the GKI group although the differences were not statistically significant. There was no significant 
difference in median total ESS score between treatment groups on admission or at 24 hours, 48 hours, and 7 days. However, the increase in median total ESS score between admission and 7 days was significant within the GKI group (44.5 to 57 ; $\mathrm{p}<0.001$, Wilcoxon rank sum) but not within the control group (49.5 to 58; $\mathrm{p}=0.15$ ). There was also a significant increase in mean plasma potassium concentration over the first 24 hours in the GKI group compared with controls (table).

\section{Discussion}

There is increasing evidence to suggest that control of hyperglycaemia in acute stroke may have beneficial effects on prognosis. ${ }^{4}$ There is also evidence suggesting that an admission systolic blood pressure of between 140 and 180 $\mathrm{mm} \mathrm{Hg}$ is associated with a better outcome than a lower or higher admission blood pressure. ${ }^{7}$ However, it is unknown whether modulation of blood pressure or glucose influences outcome after stroke or whether maintenance of euglycaemia affects the haemodynamic response to cerebral ischaemia.

Potential causes for poststroke hypertension include the stress of hospital admission, raised intracranial pressure, loss of cerebral autoregulation, damage to hypothalamic centres responsible for blood pressure control, and the direct consequences of focal cerebral hypoxia and oligaemia. The final common pathway through which blood pressure is increased in these situations is likely to be increased catabolic hormone release. Euglycaemic insulin infusion is known to influence blood pressure in healthy normotensive humans although the effect is inconsistent in that both hypotensive and hypertensive responses have been found. ${ }^{910}$ Insulin infusion also increases plasma renin activity and angiotensin II concentrations and decreases aldosterone concentrations in healthy humans, but these effects might be expected to raise rather than lower blood pressure. ${ }^{11}$ There is therefore little evidence to support a peripheral (noncerebral) site of action for the hypotensive effect of insulin infusion, suggesting that our findings may be a consequence of the central effects of insulin on ischaemic cerebral tissue.

Insulin is neuroprotective when administered in animal models of transient focal cerebral ischaemia. Insulin plays a neuroinhibitory part in most brain areas and may protect against ischaemia initiated excitatory damage by increasing cerebral $\gamma$-aminobutyric acid (GABA) concentrations. ${ }^{12}$ Insulin reduces glucose utilisation in many brain areas and may inhibit glucose phosphorylation and thus reduce local lactic acid concentration. ${ }^{13}$ Insulin also stimulates $\mathrm{Na}^{+} \mathrm{K}^{+}$-ATPase, which reduces extracellular cerebral potassium concentrations, decreases brain glucose utilisation, and reduces the risk of cerebral oedema. ${ }^{14}$ Insulin enhances cerebral noradrenaline (norepinephrine) release and inhibits reuptake thus increasing the extracellular concentration' which may attenuate ischaemic brain damage. ${ }^{15}$ Any of these mechanisms may limit the extent of the ischaemic damage and as the metabolic stress response to stroke is proportional to the extent of cerebral damage, the likely consequence is attenuation of catabolic hormone release and reduction of systolic blood pressure. ${ }^{16}$

Current opinion suggests that blood pressure should not be actively lowered in acute stroke to avoid reduction of cerebral blood flow to the ischaemic area where autoregulation is impaired. However, our study suggests that the systolic blood pressure reduction associated with GKI therapy does not cause early neurological decline. An alternative explanation for the hypotensive effect of GKI therapy is that the saline load incurred in the control group augmented blood pressure. We therefore propose to study the blood pressure response in both treatment groups further with automated electronic 48 hour ambulatory blood pressure monitoring and also in an additional control group of patients with acute stroke who will receive no saline therapy.

In summary, GKI therapy in hyperglycaemic patients with acute stroke is associated with a significant hypotensive effect to levels of systolic blood pressure that are currently thought to be associated with optimal outcome. This haemodynamic response may be a consequence of the effects of insulin on ischaemic cerebral tissue rather than insulin's peripheral hypoglycaemic effect.

JFS, JEO'C, CSG, and KGMMA planned the study. JFS and GMR randomised the participants and performed the clinical assessments. JEO'C and CSG supervised the inpatient care of study participants. JFS, CSG and JMF undertook the statistical analysis and all authors contributed to the writing of the manuscript. This study was supported by a grant from the Stroke script. This study was supported by a grant from the Stroke Association of England and Wales and a Northern and Yorkshire National Health Service Regional Training Fellowship. We thank Dr Basu and colleagues of Sunderland Royal Hospital for their help with patient recruitment and the nursing staff of the admissions unit and stroke unit for their help in implementing the trial protocols.

1 Jørgenson HS, Nakayama H, Kammersgard LP, et al. Predicted impact of intravenous thrombolysis on prognosis of general population of stroke patients: simulation model. of general population

2 Wahlgren NG. Cytoprotective therapy for acute ischaemic stroke. In: Fisher M, ed, Stroke therapy. Boston: Butterworth and Heinemann, 1999:315-50.

3 Gray CS, Taylor R, French JM, et al. The prognostic value of stress hyperglycaemia and previously unrecognised diabetes mellitus in acute stroke. Diabet Med 1987;4:23740.

4 Weir CJ, Murray GD, Dyker AG, et al. Is hyperglycaemia an independent predictor of poor outcome after stroke? Results of a long term follow up study. BMF 1997;314: 1303-6.

5 Wallace JD, Levy LL. Blood pressure after stroke. $f A M A$ 1981;246:2177-80.

6 Harper G, Castledon CM, Potter JF. Factors affecting changes in blood pressure after stroke. Stroke 1994;25: $1726-9$

7 Bath FJ, Iddenden RG, Bath PMW. How should blood pressure be managed in acute stroke? A systematic review of individual patient data from randomised controlled trials: blood pressure in acute stroke collaboration (BASC). Cerebrovasc Dis 1999;9(suppl 1):103.

8 Scott JF, Robinson GM, French JM, et al. Glucose potassium insulin (GKI) infusions in the treatment of acute stroke patients with mild to moderate hyperglycaemia: the glucose insulin in stroke trial. Stroke 1999;30:793-9.

9 Rowe JW, Young JB, Minaker KL, et al. Effect of insulin and glucose infusions on sympathetic nervous system activity in normal man. Diabetes 1981;30:219-25.

10 Anderson EA, Hoffman RP, Balon TW, et al. Hyperinsulinaemia produces both sympathetic neural activation and vasodilatation in normal humans. F Clin Invest 1991;87: vasodilatation $2246-52$.

11 Trovati M, Massucco P, Anfossi G, et al. Insulin influences the renin-angiotensin-aldosterone system in humans. Metabolism 1989;38:501-3. 
12 Shuaib A, Ijaz MS, Waqar T, et al. Insulin elevates hippocampal GABA levels during ischemia. This is independent of its hypoglycaemia effect. Neuroscience 1995; 67:809-14.

13 Gjedde A, Hansen AJ, Siemkowicz E. Rapid simultaneous determination of regional blood flow and blood brain glucose transfer in brain of rat. Acta Physiol Scand 1980;108 321-30.
14 Stahl W. The Na,K-ATPase of nervous tissue. Neurochem Int 1986;8:449-76.

5 McCaleb M, Myers RD, Singer G, et al. Hypothalamic norepinephrine in the rat during feeding and push-pull perfusion with glucose, 2-DG, or insulin. Am f Physiol 1979;236:R312-21. 16 Koide T, Wieloch TW, Siesjö BK. Circulating catecholamines modulate ischaemic brain damage. 7 Cereb Blood Flow Metab 1986;6:559-65.

\section{NEUROLOGICAL PICTURE}

\section{Widespread cerebral cavernous haemangiomata found after 24 years of intermittent symptoms}

The diagnosis of many types of cerebral pathology has been greatly facilitated by the development of MRI. We report on a 65 year old man who presented to his local casualty department with diplopia, right sided sensory disturbance, and unsteadiness. Questioning disclosed a 24 year history of intermittent diplopia of both eyes for up to 2 months at a time but always resolving completely. The patient had attributed these symptoms to a minor head injury at the age of 41 . One year before this presentation he developed a left facial nerve palsy associated with recurrent diplopia. Although the facial weakness resolved spontaneously within several weeks, his diplopia persisted. He had been fitted with corrective prisms after opthalmological review. No cerebral imaging was performed.

At this presentation the patient showed profound oscillopsia and was unable to stand without support. Further examination disclosed bilateral abducens nerve palsy with vertical nystagmus. Pinprick sensation was reduced in the ophthalmic branch of the right trigeminal nerve, and there was a left lower motor neuron-type facial nerve weakness. Evidence of right sensorineural deafness was also present. There was mild right hemiplegia and hemisensory disturbance in addition. Limb reflexes were brisk on the right with a right sided extensor plantar response.

Brain CT (figure A) showed small foci of increased attenuation throughout both hemispheres and the cerebellum which showed mild enhancement with intravenous contrast. He was initially investigated for evidence of an extracerebral primary neoplasm-none was found. T1 weighted MRI (figure B) was equally unhelpful in disclosing the true extent of his pathology, which can be clearly seen on the T2 weighted images (figure C). The numerous haemorrhagic lesions of varying ages, as suggested by the presence of lesions with darker ring patterns representing haemosiderin deposits, formed a striking Swiss cheese-like appearance.

This appearance is characteristic of cerebral cavernous haemangiomata, whose natural history of intermittent haemorrhage is well described. Seizure is the most common presenting symptom, and most lesions are solitary, multiple cavernomas tending to be more common in familial clusterings (our patient did not report any such family history).

This also serves as an example of the variable sensitivity of MRI to certain pathology depending on the image acquisition parameters.

M R TURNER

Academic Neurosciences Centre,

Institute of Psychiatry,

De Crespigny Park,

London, SE5 8AF, UK

W N MACLEOD

Hurstwood Park Neurological Centre,

Haywards Heath,

West Sussex, RH16 4EX, UK

Correspondence to: Dr M R Turner

m.turner@iop.kcl.ac.uk
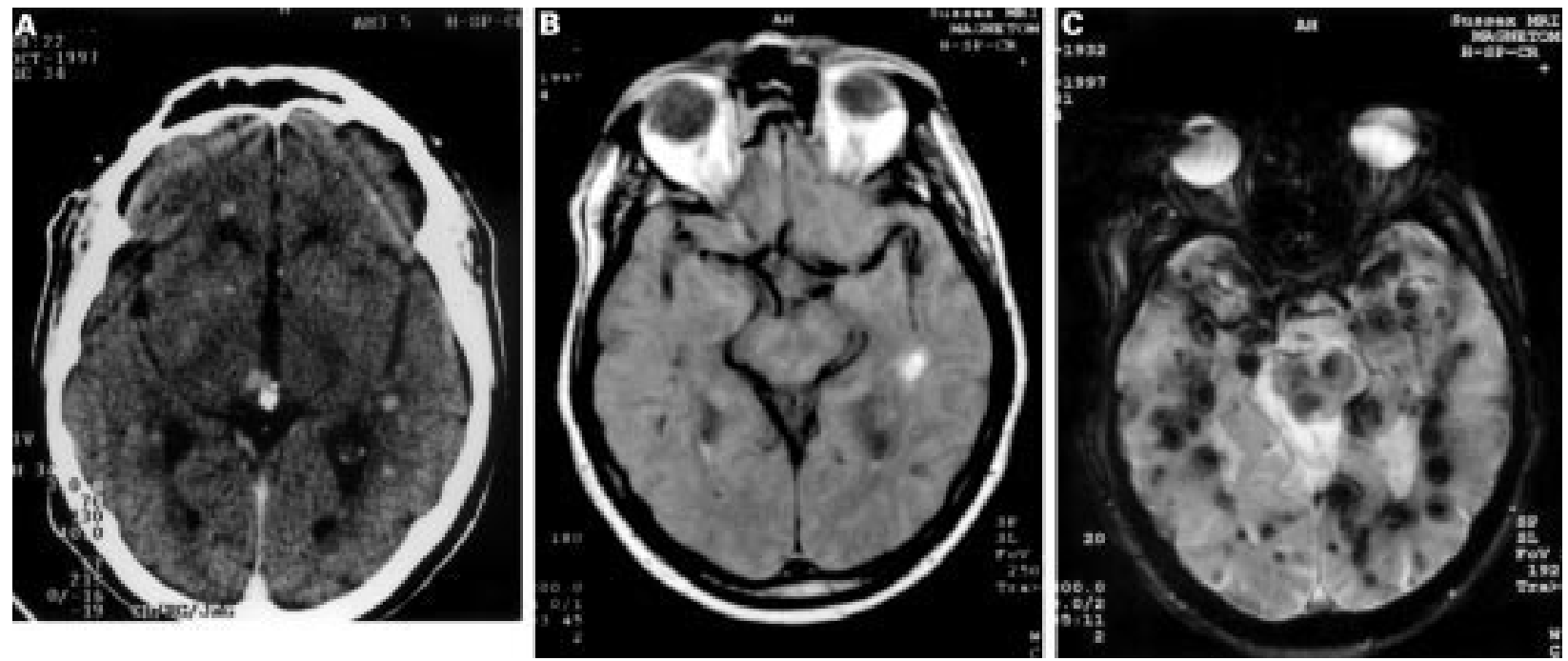